\title{
Evaluating mentoring outcomes from the perspective of entrepreneurs and small business owners
}

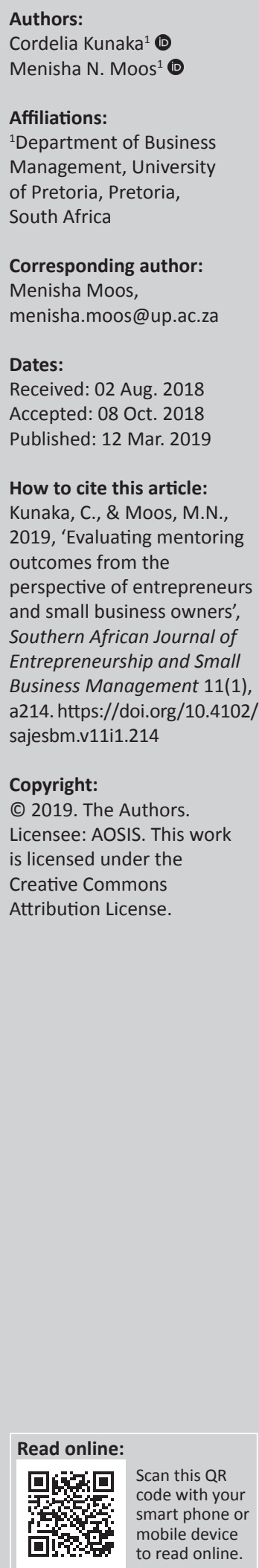

Background: Mentoring as support for both the business and the individual entrepreneur or small business owner is important for the continued perseverance of the entrepreneurial journey.

Aim: Different mentoring outcomes were evaluated to establish what is being gained from the mentoring relationships to encourage other entrepreneurs and small business owners to pursue mentoring relationships.

Setting: South African entrepreneurs and small business owners who were currently being mentored or had been mentored.

Method: The study used a survey research design that consisted of 209 qualifying entrepreneurs and small business owners. An online questionnaire was used to collect the data.

Results: The results show that there is a relationship between the different mentoring outcomes (skills transfer outcomes, knowledge transfer outcomes, entrepreneur resilience outcomes and business outcomes). In addition, it was established that as the mentoring relationship goes through the different phases of initiation, cultivation, separation and redefinition, mentoring outcomes such as skills transfer and entrepreneur resilience are independently attained.

Conclusion: Understanding the outcomes of mentoring will encourage more participation in the field of mentoring for South African mentors, entrepreneurs and small business owners through awareness of the benefits thereof as well as how mentoring can form a strong supporting mechanism. This research makes a theoretical contribution by naming and grouping mentoring outcomes into four categories, such as skills transfer outcomes, knowledge transfer outcomes, entrepreneur resilience outcomes and business outcomes.

\section{Introduction}

Mentoring is important for entrepreneurs and small business owners to develop sustainable businesses that create jobs (Botha \& Esterhuyzen 2012; Herrington \& Kew 2015). Previous studies on mentoring in a South African context focused on profiling mentors (Martin 2008; Watson 2004), evaluating the effectiveness of mentoring programmes (Swanepoel, Strydom \& Nieuwenhuizen 2010), perceptions of mentoring on venture growth (Ayer 2010) and selfefficacy (Cline 2011). Botha and Esterhuyzen (2012) suggest using keen, skilled small business owners as mentors to increase the existing number of mentors that can help emerging entrepreneurs to grow successful businesses. They established the willingness of small business owners to act as business mentors.

Each entrepreneur or small business owner is different and requires diverse types of mentoring support and skills (Memon et al. 2015). There is always a need for effective support mechanisms for all stages of the entrepreneurial process to advance the continued existence of businesses (St-Jean \& Audet 2012). Challenges encountered, such as selling, marketing and raising funds (Han et al. 2012), require that the entrepreneur seeks external advice to remain relevant and successful. Kamyabi and Devi (2011) revealed the use of external accountants as support by small and medium enterprises (SMEs) to fill an internal human resource gap and be competitive in their environments. Entrepreneurs intending to improve knowledge and skills in areas such as marketing, business management, profits, turnover, employment and market coverage are more likely than others to pursue and benefit from external advice or support (Davies 2017; Kyrgidou \& Petridou 2013).

Understanding mentoring outcomes will encourage more participation in mentoring for South African mentors, entrepreneurs and small business owners through awareness of the benefits 
and how mentoring forms a strong support mechanism. As suggested by Nieman and Nieuwenhuizen (2009:13), 'although entrepreneurs have the natural ability to identify opportunities and establish the business, successful management of the business might require the assistance of specialists, training and employees'. Aligning expectations, understanding the mentoring process and mentoring outcomes enhance the mentoring relationship (Matabooe, Venter \& Rootman 2016).

Key concepts used in this study include mentoring, mentoring outcomes, entrepreneur, entrepreneurship and small business. Mentoring consists of one-on-one support, influencing entrepreneur behaviour as a form of training shown to increase the confidence and risk-taking capacity of entrepreneurs (Koopman 2013; Radu Lefebvre \& RedienCollot 2013; St-Jean \& Audet 2012; Triodos Facet 2011). In reviewing organisational and individual outcomes, McKevitt and Marshall (2015:266) describe outcomes as 'actionable knowledge' which rises from mentoring because it is a relationship. An entrepreneur appreciates and follows opportunities through gathering and organising resources to create high-potential businesses. They accept and manage risk, developing markets through creativity and innovation (Nieman \& Nieuwenhuizen 2009; Timmons \& Spinelli 2009).

Entrepreneurship is defined as the process of transformation of opportunities using existing resources and it involves identifying an opportunity, making a product, growing the venture, taking risks and producing reward/s for the entrepreneur and stakeholders (Ayer 2010; Gwija, Eresia-Eke \& Iwu 2014; Nieman \& Nieuwenhuizen 2009). The National Small Business Act (1996) defines a small business as:

\begin{abstract}
...a separate and distinct business entity including cooperative enterprises and non-governmental organisations managed by one owner or more which including its branches or subsidiaries if any, is predominantly carried on in any sector or subsector of the economy and can be classified as micro, very small, small or medium enterprises by satisfying the criteria opposite the relevant size or class. (p. 2)
\end{abstract}

In the next section, the literature review will be discussing mentoring and the Social Cognitive Learning Theory, mentoring outcomes and the phases of mentoring.

\section{Literature review}

\section{Mentoring and Social Cognitive Learning Theory}

Recognising the importance of learning for entrepreneurs and small business owners, this study refers to Bandura's Social Cognitive Learning Theory as it emphasises behavioural learning. Harinie et al. (2017) exhibit three underlying assumptions of the Social Cognitive Learning Theory as:

- individuals learn by imitating behaviour displayed by models in their environment

- learning occurs through the linkage between behaviour, the individual and the environment

- the outcome of learning behaviour is visually and verbally coded from everyday behaviour.
Furthermore, Bayron (2013) highlights that learning occurs through interaction with others, reinforcement, observation of role models and imitating behaviour. Learning occurs when a person observes another individual, or models behaviour in a certain way. Illustrating learning within the environment, Steele (2016) explains that learning ought to suit the context of the business and the entrepreneur's preferred approach.

Brien and Hamburg (2014) link social learning to how SMEs favour interaction and learning by the doingapproach, in addition to the formal methods. This is further demonstrated by entrepreneurs in a study by Stavropoulou and Protopapa (2013), who promote learning from a mentor's experience and the likelihood of transferring meaningful, necessary new learning to business. Mentoring can be considered as a form of social learning for the entrepreneurs and small business owners; their interaction, observation and imitation of mentors can accentuate entrepreneurial behaviour.

\section{Mentoring outcomes}

Outcomes can be what the mentee stands to gain, such as support, knowledge and expert advice. Rigg and O'Dwyer (2012) highlight mentoring outcomes as knowledge transfer, reflection and construction of knowledge. Nicoleta and Chioncel (2014) confirm that competences, skills and abilities can be transferred through mentoring. Other words used to describe mentoring outcomes were investigated. Mentoring outcomes are sometimes referred to as benefits (Brien \& Hamburg 2014; Makin 2012; Sijde \& Weijman 2013), the value of mentoring (Poulsen 2013) and the consequences or impacts of mentoring (Mills, Barakat \& Vyarnam 2013; St-Jean \& Audet 2009). Therefore, mentoring outcomes can be knowledge, expert advice, competencies, skills and abilities. Entrepreneurship articles with these descriptions were reviewed, a list made and then categorised. The literature review on mentoring outcomes is presented in four categories, which is summarised as skills transfer outcomes, knowledge transfer outcomes, entrepreneur resilience outcomes and business outcomes, as presented in Table 1.

Skills transfer outcomes assist entrepreneurs to identify and evaluate possible business opportunities, develop clearer business vision, have the ability to manage a business and achieve goals and networks. Knowledge transfer outcomes will result in understanding accounts, managing operations and human resource management. Entrepreneur resilience outcomes involve validating entrepreneurial self-image, increasing self-efficacy and confidence, fostering entrepreneurial culture and encouraging personal development. Business outcomes include increased productivity levels, improved post-sales follow-up, increased product range, increased sales revenue, increased profitability, reduced costs and improved business survival. 
TABLE 1: Categories of mentoring outcomes.

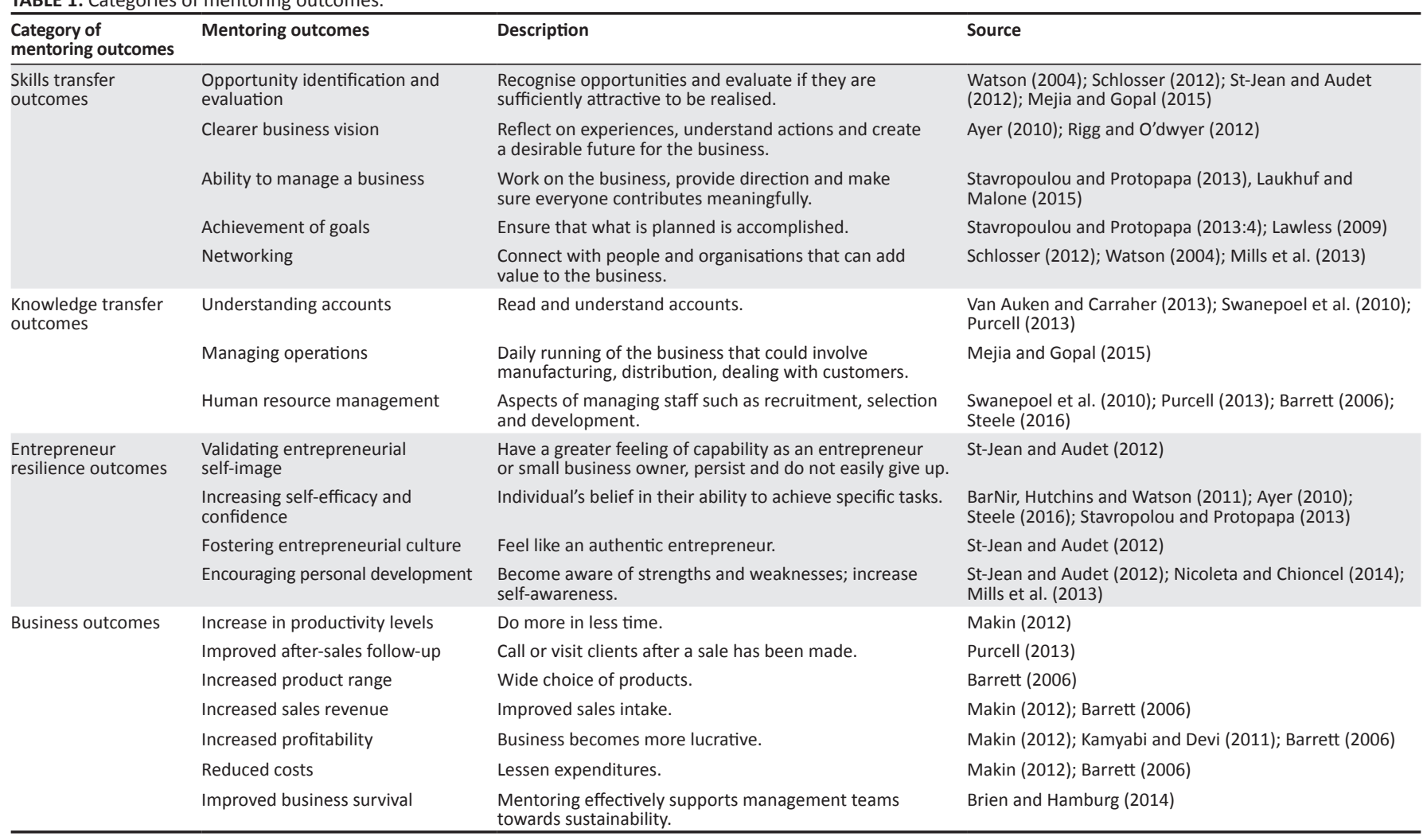

Note: Please see the full reference list of the article, Kunaka, C., \& Moos, M.N., 2019, 'Evaluating mentoring outcomes from the perspective of entrepreneurs and small business owners', Southern African Journal of Entrepreneurship and Small Business Management 11(1), a214. https://doi.org/10.4102/sajesbm.v11i1.214, for more information.

From the literature the following research hypothesis was formulated:

- Research hypothesis 1: There is a relationship between the different mentoring outcomes (skills transfer outcomes, knowledge transfer outcomes, entrepreneur resilience outcomes and business outcomes).

To test the different mentoring outcomes, the following six statistical hypotheses were formulated:

- H1A: There is a relationship between skills transfer outcomes and knowledge transfer outcomes.

- H1B: There is a relationship between skills transfer outcomes and entrepreneur resilience outcomes.

- H1C: There is a relationship between skills transfer outcomes and business outcomes.

- H1D: There is a relationship between knowledge transfer outcomes and entrepreneur resilience outcomes.

- H1E: There is a relationship between knowledge transfer outcomes and business outcomes.

- H1F: There is a relationship between entrepreneur resilience outcomes and business outcomes.

\section{Phases of mentoring}

The phases of the mentoring relationship are significant; any relationship goes through a formation period when people get to know each other, a time when the relationship is operating at an efficient level and then a time when it needs to be dissolved. The phase in which the mentee is interviewed for the study could also influence their response. Mentees in different phases of mentoring will perceive different levels of support from their mentors as the interaction levels change in every phase. Table 2 summarises the phases of mentoring highlighted by Kram (1983), Memon et al. (2015) and Poulsen (2013).

In a seminal paper, Kram (1983) describes four distinct phases of mentoring: the initiation stage, the cultivation stage, the separation phase and the redefinition phase. Poulsen (2013) also describes four phases of mentoring: the preparation phase, the establishing the relationship phase, the learning and developing phase and the ending phase. Leidenfrost et al. (2014) position Kram's phases from the mentee's perspective in their study of peer mentoring on mentees. The importance of Kram's phases of mentoring is revealed as creating effective mentoring relationships with every relationship going through the different phases, although the time taken in each of the phases might differ (Memon et al. 2015).

The researcher uses the phases of mentoring, as described by Kram, influenced by the positioning done by Leidenfrost et al. (2014) and Memon et al. (2015), as this research is from the mentee's perspective (entrepreneurs and small business owners). The literature posits that entrepreneurial learning starts in the cultivation stage (Memon et al. 2015). Although the mentoring outcomes are not specified in the different stages, the following hypotheses were formulated to guide the study:

- Research hypothesis 2: There is a relationship between the phases of mentoring and the different mentoring outcomes. 
TABLE 2: Phases of mentoring.

\begin{tabular}{|c|c|c|}
\hline Source & Phase of mentoring & Description \\
\hline \multirow[t]{4}{*}{ Kram (1983) } & Initiation phase & First 6-12 months when the relationship is formed and begins to provide meaning. Not much mentoring value is gained at this stage. \\
\hline & Cultivation phase & $\begin{array}{l}\text { A period of } 2-5 \text { years of maximum interaction. The mentee takes full advantage of mentoring functions and learning occurs. } \\
\text { The mentor encourages and safeguards the mentee during this stage. }\end{array}$ \\
\hline & Separation phase & $\begin{array}{l}\text { Occurs } 6 \text { months to } 2 \text { years after structural change in the relationship. The mentee becomes more independent as the mentor } \\
\text { roles decrease. }\end{array}$ \\
\hline & Redefinition phase & $\begin{array}{l}\text { An unspecified period after separation occurs. Termination of the relationship may occur or the relationship may become } \\
\text { more informal with occasional meetings. }\end{array}$ \\
\hline \multirow{4}{*}{$\begin{array}{l}\text { Memon et al. } \\
\text { (2015) }\end{array}$} & Initiation stage & Discusses and clarifies common goals, shared values and dreams. \\
\hline & Cultivation stage & First stage of entrepreneurial learning and development. There is better interaction. \\
\hline & Closure/separation stage & $\begin{array}{l}\text { Generally, it defines the end of the mentoring relationship. Mutual agreement to separate is important; mentee might have } \\
\text { redefined goals in which the mentor is not suitable or wants to be independent. Mentor might want the mentee to learn } \\
\text { individually. }\end{array}$ \\
\hline & Redefinition stage & $\begin{array}{l}\text { Both mentor and mentee should want the relationship to carry on. Successful achievement of goals during the mentoring } \\
\text { relationship should have occurred. Formal/mentoring program relationships are unlikely to redefine. New mentoring } \\
\text { relationship develops. }\end{array}$ \\
\hline \multirow[t]{4}{*}{ Poulsen (2013) } & Preparation phase & $\begin{array}{l}\text { Involves making the decision to enter the mentoring relationship. The mentee evaluates what they need to learn and if the } \\
\text { programme will meet that need. Mentors consider how they can benefit from taking on the mentor role. An evaluation of their } \\
\text { own competencies, time and the motivation that they bring to the mentoring relationship is also important so that they can } \\
\text { contribute meaningfully. }\end{array}$ \\
\hline & $\begin{array}{l}\text { Establishing the relationship } \\
\text { phase }\end{array}$ & $\begin{array}{l}\text { Begins at first meeting. Mentees and mentors clarify mutual expectations, get to know each other and explore motivation for } \\
\text { entering the programme. It is important to establish a good relationship with openness and trust. }\end{array}$ \\
\hline & $\begin{array}{l}\text { Learning and developing } \\
\text { phase }\end{array}$ & $\begin{array}{l}\text { Results in new understanding and new insights. Real learning takes place. It is critical in this phase that the mentee takes action } \\
\text { leading to new behaviour and new competencies. }\end{array}$ \\
\hline & Ending phase & $\begin{array}{l}\text { Rounds up the relationship in different ways. Some choose to continue the mentoring relationship, become friends or pursue a } \\
\text { different kind of relationship. Choosing to completely part ways is also acceptable. }\end{array}$ \\
\hline
\end{tabular}

To test the phases of mentoring with each separate mentoring outcome, the following statistical hypotheses were formulated:

- H2A: There is a relationship between the phases of mentoring and skills transfer outcomes.

- H2B: There is a relationship between the phases of mentoring and knowledge transfer outcomes.

- H2C: There is a relationship between the phases of mentoring and entrepreneur resilience outcomes.

- H2D: There is a relationship between the phases of mentoring and business outcomes.

\section{Problem investigated}

Mentoring outcomes have not been properly illustrated in the South African context. Evaluating the mentoring outcomes for entrepreneurs and small business owners will gather reasons to encourage support through mentoring. It will give credence to the different organisations offering mentoring in South Africa, such as banks, corporate companies, government support institutions, industry trade organisations and private support organisations.

\section{Research design and methodology}

The research question of the study is: 'How has mentoring previously assisted or is currently assisting entrepreneurs and small business owners to attain mentoring outcomes'?

The primary research objective is to evaluate mentoring outcomes from the perspective of entrepreneurs and small business owners.

The secondary research objectives are as follows:

- to determine if there is a relationship between the skills transfer outcomes and each of the other mentoring outcomes (knowledge transfer outcomes, entrepreneur resilience outcomes and business outcomes)
- to determine if there is a relationship between the knowledge transfer outcomes and each of the other mentoring outcomes (skills transfer outcomes, entrepreneur resilience outcomes and business outcomes)

- to determine if there is a relationship between the entrepreneur resilience outcomes and each of the other mentoring outcomes (skills transfer outcomes, knowledge transfer outcomes and business outcomes)

- to determine if there is a relationship between the business outcomes and each of the other mentoring outcomes (skills transfer outcomes, knowledge transfer outcomes, and entrepreneur resilience outcomes)

- to determine if there is a relationship between the phases of mentoring and the different mentoring outcomes (skills transfer outcomes, knowledge transfer outcomes, entrepreneur resilience outcomes and business outcomes).

\section{Research design}

The quantitative research design was utilised. The study adopted a probability sampling strategy as inferences can be made for the population from the cases surveyed (Cooper \& Schindler 2011). Entrepreneurs and small business owners that are being mentored or that have been mentored before were considered. The study's sample was collected using a simple random sampling method. The sampling was done without replacement; a unique code was generated for each participant. Once the participant had completed the survey to the end, they were not allowed to repeat the survey. Two disqualifying questions were added into the survey to ensure that only the people who fall within the target group completed the survey. The disqualification questions were as follows:

- 'Do you currently own a business?'

- 'Have you been mentored before or are you currently being mentored?' 
If a participant replied with 'no' to either of these questions, they were immediately disqualified from completing the survey.

\section{Research method}

Email invitations to participate in the online survey were sent out to entrepreneurs and small business owners. This was a communication study and the qualifying respondents proceeded to complete the online questionnaire.

The following characterised the data collection:

- Qualifying participants that completed the survey were 209 of the 300, therefore 91 left the survey incomplete.

- The completion rate was $70 \%$.

The questionnaire was informed by the literature reviewed. Questions were adjusted as per the short descriptions of the mentoring outcomes in the literature review section of this article. The respondents were asked to choose from a scale of 1 (totally disagree) to 5 (totally agree) and 6 (not applicable). A Likert-type scale was used to enable easy data analysis. During data analysis, data for the mentoring outcomes in the Likert scales were reduced to nominal values, for example:

- $\quad$ strongly disagree + disagree $=$ disagreement; and

- $\quad$ strongly agree + agree $=$ agreement .

\section{Measurement of research questionnaires}

Mentoring outcomes have been divided into the following four categories:

- Skills transfer outcomes, consisting of a combined score measuring opportunity identification and evaluation, clearer business vision, ability to manage a business, achieve goals, developing a business plan and networking.

- Knowledge transfer outcomes, consisting of a combined score measuring financial management, operations management and human resource management.

- Entrepreneur resilience outcomes, made up of a combined score measuring validation of one's entrepreneurial selfimage, lowered sense of isolation, increased sense of self-efficacy and confidence, perseverance, fostering entrepreneurial culture and personal development.

- Business outcomes, made up of a combined score measuring increases in productivity levels, improved after-sales follow-up, increased product range, increases in sales revenue, increases in profitability, reduced costs and business survival.

\section{Data analysis}

Pilot testing of the questionnaires was done to assess, prior to data collection, whether the research instrument measured what it was supposed to measure and would supply dependable results. The researcher followed the three steps that assess content validity through judgement and careful definition of the topic, the items to be scaled and the scales to be used (Cooper \& Schindler 2011). Reliability was enhanced by using online databases of entrepreneurs and small business owners. Only fully completed surveys were used for data analysis.

Construct validity was performed using factor analysis. This seeks to investigate whether several variables belong together and can be grouped together into a set, called a factor. They are then treated as belonging to a statistically similar concept (Lee 2015). In this study, confirmatory factor analysis (CFA) was used. A set of constructs that belong together were put into SPSS (Statistical Package for Social Sciences) computer software to test the appropriateness of the researcher's assumptions of how they fit together.

An exploratory factor analysis was conducted, using principal component extraction and varimax rotation, to determine the unidimensionality of each of the mentoring outcome constructs. The Kaiser-Meyer-Olkin measure of sampling adequacy was between 0.797 and 0.910 , which are all above the recommended threshold of 0.5. The Bartlett's test of sphericity was significant $(p<0.001)$ for each of the constructs, therefore indicating that a factor analysis was appropriate (Beavers et al. 2013).

The analysis confirmed unidimensionality for all the mentoring outcome constructs, as the analysis identified only one factor based on the eigenvalue criterion (eigenvalue greater than 1), respectively, for all the constructs. The factor explains between $61.736 \%$ and $73.538 \%$ of the variance. The results of the factor analysis are shown in Table 3.

Using Cronbach's alpha, the internal consistency (reliability) for the four constructs was found to be between 0.894 and 0.931 . As these values are above the acknowledged threshold of 0.7 , it was deemed satisfactory. Factor-based scores were subsequently calculated as the mean score of the variables included in each factor.

The majority of the measurement scales were dichotomous, nominal or ratio and this data will be represented through tables and graphs using frequency and percentages. Mentoring outcomes of interval data and correlations will be presented. The software SPSS will be used to conduct relevant statistical modelling required.

\section{Pearson's correlation coefficient}

Pearson's $r$ is a method for investigating relationships between interval/ratio variables; a correlation exists when one variable increases and another variable either increases or decreases. Being either positive or negative indicates the direction of the relationship. The closer the coefficient is to one (1), the stronger the relationship; the closer to zero (0), the weaker the relationship (Bryman \& Bell 2015). A positive number indicates a positive correlation, as one variable increases, the other variable also increases. 


\begin{tabular}{|c|c|c|c|c|c|}
\hline \multirow[t]{2}{*}{ Construct } & \multicolumn{2}{|c|}{ KMO and Bartlett's Test } & \multirow{2}{*}{$\begin{array}{l}\% \text { of variance } \\
\text { explained }\end{array}$} & \multirow{2}{*}{$\begin{array}{l}\text { Factor } \\
\text { loading }\end{array}$} & \multirow{2}{*}{$\begin{array}{l}\text { Cronbach's } \\
\text { alpha }\end{array}$} \\
\hline & $n$ & $p$ & & & \\
\hline Skills transfer outcomes & 0.905 & 0.000 & $61.736 \%$ & - & 0.895 \\
\hline Recognise opportunities & - & & - & 0.821 & - \\
\hline Check to appreciate if opportunities can be realised & - & & - & 0.842 & - \\
\hline Understand the desirable future for the business & - & & - & & - \\
\hline Work on the business, making sure everyone contributes meaningfully & - & & - & 0.786 & - \\
\hline Accomplish what was planned & - & & - & & - \\
\hline Set direction for the business & - & & - & 0.726 & - \\
\hline Connect with people and organisations that can add value to the business & - & & - & & - \\
\hline Knowledge transfer outcomes & 0.797 & 0.000 & $70.672 \%$ & - & 0.894 \\
\hline Understand accounts & - & & - & 0.754 & - \\
\hline Run the business daily & - & & - & 0.806 & - \\
\hline Recruit staff & - & & - & 0.859 & - \\
\hline Manage staff & - & & - & 0.907 & - \\
\hline Entrepreneur resilience outcomes & 0.899 & 0.000 & $73.538 \%$ & - & 0.926 \\
\hline Have a greater feeling of capability & - & & - & 0.790 & - \\
\hline Have someone to talk to and bounce off ideas & - & & - & 0.792 & - \\
\hline Have belief in my individual ability to achieve specific tasks & - & & - & 0.898 & - \\
\hline Persist in my business and not easily give up & - & & - & 0.898 & - \\
\hline Am aware of my strengths and weaknesses & - & & - & 0.884 & - \\
\hline Have a sense of increased self-awareness & - & & - & 0.875 & - \\
\hline Business outcomes & 0.910 & 0.000 & $70.867 \%$ & - & 0.931 \\
\hline Increase productivity levels & - & & - & 0.818 & - \\
\hline Improve after-sales follow-up & - & & - & 0.872 & - \\
\hline Increase product range & - & & - & 0.855 & - \\
\hline Increase sales revenue & - & & - & 0.863 & - \\
\hline Increase profitability & - & & - & 0.887 & - \\
\hline Reduce costs & - & & - & 0.788 & - \\
\hline
\end{tabular}

KMO, Kaiser-Meyer-Olkin measure.

A negative correlation as one variable increases, the other variable decreases with a correlation of +1 or -1 indicating a perfect correlation (Leedy \& Omrod 2013).

\section{Regression analysis}

Regression enables the researcher to estimate association between the variables (Lee 2015). In this study, regression will be conducted with mentoring outcomes (skills transfer outcomes, knowledge transfer outcomes, entrepreneur resilience outcomes and business outcomes) being the dependent variables. The independent variables are phases of mentoring and number of mentoring relationships.

\section{Research findings}

In this section, data will be presented based on the response to the questions presented to the entrepreneurs and small business owners that participated in the online survey.

\section{Descriptive statistics}

\section{Demographics of the research sample}

Table 4 highlights the demographic variables of the entrepreneurs and small business owners including gender, ethnic group and level of education. Details of the business venture included the number of full-time and part-time paid employees and industry.
The demographic profile of the gender of the 209 entrepreneurs and small business owners that responded to the survey comprised $69.90 \%$ (146) males and $30.10 \%$ (63) females. The results of the current study indicate that $69.40 \%$ (145) of the respondents were black people, $19.1 \%$ (40) were white people, $6.2 \%$ (13) were mixed-race people and $3.2 \%(8)$ were Indian people. This racial composition is consistent with black entrepreneurs being more likely to seek mentoring in South Africa as they form the largest number of early-stage entrepreneurs (Herrington \& Kew 2015).

Education increases self-efficacy and self-confidence, increasing chances of people starting up and surviving in business. In relation to this study, education would increase the transfer of mentoring outcomes. Herrington and Kew (2015) accentuate the importance of all forms of education in developing entrepreneurial competencies.

\section{Demographic details of the business venture}

Number of employees and industry were evaluated to ascertain demographic details of the business venture. Entrepreneurs and small business owners play an important role of contributing towards job creation (Botha \& Esterhuyzen 2012). Early-stage entrepreneurs with medium-to-high growth objectives in one particular study were expected to create six or more jobs (Herrington \& Kew 2015). 
In this study, indicating the number of full-time or part-time employees, it was ascertained that $44 \%$ (92) respondents had full-time paid employees and 45.5\% (95) respondents had part-time paid employees. In a review of effectiveness of a mentorship programme, Makhado (2015) observed that $8.3 \%$ of the respondents work alone, $75 \%$ of the businesses had 2-5 employees and $16.7 \%$ had 6-20 employees. The results align to this study where most of the entrepreneurs and small business owners employed 1-4 full-time or parttime paid employees.

Figure 1 presents the 12 categories as per the schedule in the National Small Business Act of 1996 that were used to analyse the industry that the entrepreneurs and small business owners participate in.

\begin{tabular}{lcc} 
TABLE 4: Demographics of research sample. & & \\
\hline Variable & $\%$ & Frequency $(N)$ \\
\hline Gender & & \\
Male & 69.90 & 146 \\
Female & 30.10 & 63 \\
Ethnic group & & \\
Black people & 69.40 & 145 \\
Mixed-race people & 6.20 & 13 \\
Indian people & 3.80 & 8 \\
White people & 19.10 & 40 \\
Other & 1.40 & 3 \\
Age & & \\
18-24 & 1.90 & 4 \\
25-34 & 22.50 & 47 \\
35-44 & 38.30 & 80 \\
45-54 & 22.00 & 46 \\
55-64 & 13.40 & 28 \\
>64 & 1.90 & 4 \\
Level of education & & 21 \\
Less than matric & 6.70 & 28 \\
Matric (grade 12) & 9.60 & 20 \\
Certificate and/or national diploma & 42.10 & 88 \\
University degree (3-year degree) & 13.40 & 28 \\
University honours degree & 13.40 & \\
University master's degree & 10.00 & \\
University doctoral degree & 1.00 & 3.80 \\
Other & & \\
\hline & & 28 \\
\hline
\end{tabular}

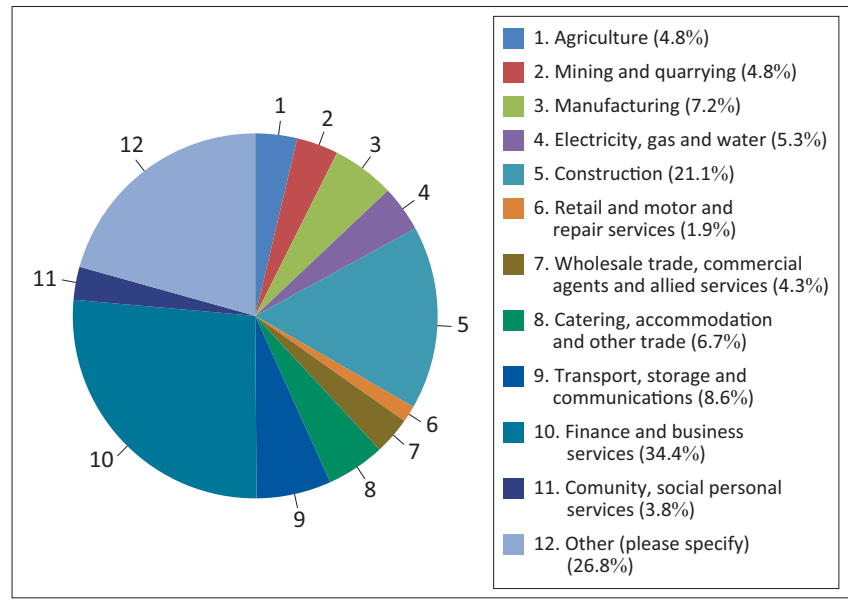

FIGURE 1: Industry that surveyed entrepreneurs and small business owners are involved in.
From Figure 1, finance and business services was the most common single industry with $72(34.4 \%)$ respondents, the lowest was retail and motor and repair services with $4(1.9 \%)$ respondents.

Analysing industry, Herrington and Kew (2015) show that South African businesses are active in the overtraded consumer services industry, which reduces their profit margins. Equipped with this knowledge, mentors could consider redirecting entrepreneurs and small business owners to diversify into more profitable industries such as communication, financial services and technology. Operating in vulnerable industries decreases the sustainability of businesses but people often start businesses that have low barriers to entry in terms of skills and capital required. Support is required so that more entrepreneurs and small business owners can operate in the robust profitable industries.

\section{Findings regarding mentoring}

Entrepreneurs and small business owners sometimes engage in more than one mentoring relationship. Results for the number of mentoring relationships are presented in Figure 2.

The majority of the respondents $73.7 \%$ (154) had one or two mentoring relationships. Only $8.10 \%$ (17) had more than five mentoring relationships. Reviewing whether or not the entrepreneurs and small business owners were currently in a mentoring relationship, $53.6 \%$ (112) were currently in a mentoring relationship while $46.6 \%$ (97) had been in a mentoring relationship in the past.

Findings indicated that a strong majority (78.5\% [164]) of respondents had male mentors. This is generally consistent with the research done by Watson (2004), which found that $81.1 \%$ of mentors in South Africa were male and only $18.9 \%$ were female. However, this survey reveals a slight increase in female mentors. This could be as a result of more women being involved in entrepreneurship.

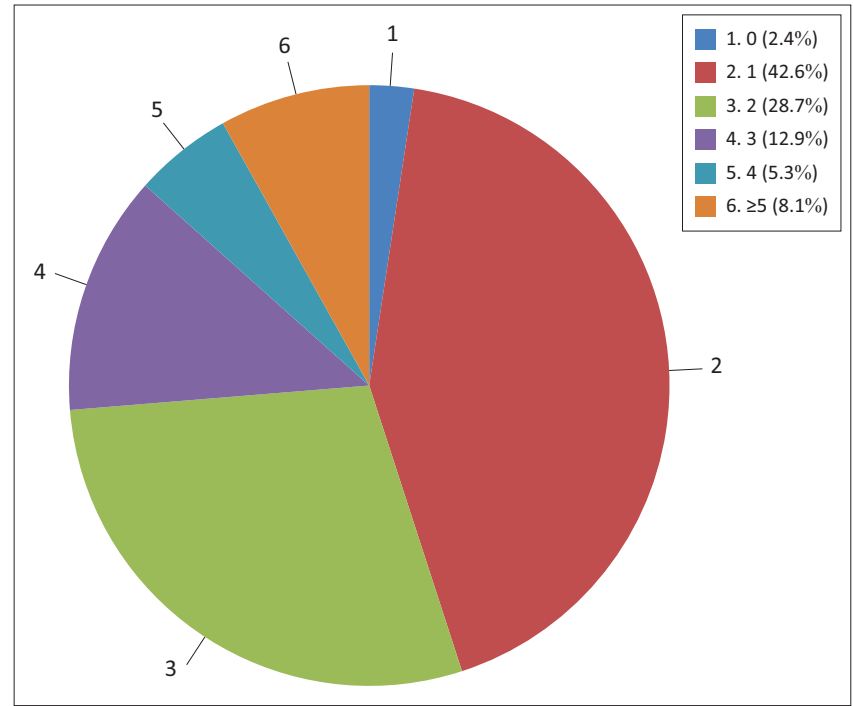

FIGURE 2: Number of mentoring relationships. 
Other entrepreneurs or small business owners were providing the most mentoring, with $34 \%$ (71) of mentees having received or currently receiving mentoring from other entrepreneurs or small business owners. The results in this study highlight that other entrepreneurs and small business owners are being used more as mentors than formal institutions. This could be as a result of the need of mentees to learn from the experience of mentors that have an appreciation of business (Moulson 2015).

\section{Ethical consideration}

The data collection process only commenced after the ethical clearance application was approved, and a permit number $12292550 / 2016$ authorising the study was issued. Each respondent was required to provide their consent prior to completing the online questionnaire. The purpose of the study, accentuating that participation in the study was voluntary and that the respondent could withdraw at any time, as well as providing assurances of anonymity and confidentiality was explained in a cover letter. Furthermore, no incentives were given to respondents for their participation in the study.

\section{Discussion of findings Research hypothesis 1: Mentoring outcomes}

Each of the six possible relationship combinations of mentoring outcomes will be tested separately. As the data were continuous, Pearson's correlation coefficient for all pairs of variables was calculated.

The Pearson correlation coefficient, statistical significance and the number of observations used are shown in Table 5.

From Table 5, the results show that:

- the correlation coefficients $(r)$ between skills transfer outcomes and each of the other three variables - knowledge

TABLE 5: Correlations between the different mentoring outcomes.

\begin{tabular}{|c|c|c|c|c|c|}
\hline $\begin{array}{l}\text { Mentoring } \\
\text { outcomes }\end{array}$ & Statistical test & $\begin{array}{c}\text { Skills } \\
\text { transfer } \\
\text { outcomes }\end{array}$ & $\begin{array}{l}\text { Knowledge } \\
\text { transfer } \\
\text { outcomes }\end{array}$ & $\begin{array}{l}\text { Entrepreneur } \\
\text { resilience } \\
\text { outcomes }\end{array}$ & $\begin{array}{l}\text { Business } \\
\text { outcomes }\end{array}$ \\
\hline \multirow{3}{*}{$\begin{array}{l}\text { Skills transfer } \\
\text { outcomes }\end{array}$} & Pearson correlation & 1 & $0.637^{*}$ & $0.616 *$ & $0.720 *$ \\
\hline & Sig. (two-tailed) & - & 0.000 & 0.000 & 0.000 \\
\hline & $N$ & 209 & 209 & 209 & 209 \\
\hline \multirow{3}{*}{$\begin{array}{l}\text { Knowledge } \\
\text { transfer } \\
\text { outcomes }\end{array}$} & Pearson correlation & - & 1 & $0.745^{*}$ & $0.745 *$ \\
\hline & Sig. (two-tailed) & - & - & 0.000 & 0.000 \\
\hline & $N$ & - & 209 & 209 & 209 \\
\hline \multirow{3}{*}{$\begin{array}{l}\text { Entrepreneur } \\
\text { resilience } \\
\text { outcomes }\end{array}$} & Pearson correlation & - & - & 1 & $0.627^{*}$ \\
\hline & Sig. (two-tailed) & - & - & 0.000 & 0.000 \\
\hline & $N$ & - & - & 209 & 209 \\
\hline \multirow{3}{*}{$\begin{array}{l}\text { Business } \\
\text { outcomes }\end{array}$} & Pearson correlation & - & - & - & 1 \\
\hline & Sig. (two-tailed) & - & - & - & 0.000 \\
\hline & $N$ & - & - & - & 209 \\
\hline
\end{tabular}

Sig., significance.

*, Correlation is significant at the 0.01 level (two-tailed) transfer outcomes, entrepreneur resilience outcomes and business outcomes - are (0.637), (0.616) and (0.720), respectively. These coefficients show a strong positive linear relationship between skills transfer outcomes and the other three types of outcomes

- the correlation coefficients $(r)$ of knowledge transfer outcomes with the other two types of outcomes are entrepreneur resilience outcomes (0.519) and business outcomes (0.745). These coefficients also show a strong positive linear relationship

- the correlation coefficient $(r)$ of entrepreneur resilience outcomes with business outcomes is (0.627). The coefficient shows a strong positive linear relationship.

All the calculated Pearson correlation coefficients were statistically significant at the $1 \%$ level of significance $(p=0.000$ for all coefficients). All the relationships showed a strong positive correlation as summarised in Table 6 .

Research hypothesis 1 was supported. It was establishing that there is a relationship between the different mentoring outcomes (skills transfer outcomes, knowledge transfer outcomes, entrepreneur resilience outcomes and business outcomes).

This is a practical finding because skills transfer outcomes such as setting direction for the business/accomplishing what was planned lead towards knowledge transfer outcomes such as running the business, recruiting, developing and managing staff. These result in business outcomes, such as increase in sales revenue, profitability and productivity levels, as well as improved after-sales follow-up and reducing costs, which can all increase the chances of the business surviving. As the business continues to survive, the entrepreneur or small business owner develops greater feelings of capability and encouragement not to give up.

The literature does not show the relationships between the different mentoring outcomes; therefore, the findings illustrated in this study are making a theoretical contribution to the field of mentoring in small business and entrepreneurship.

\section{Research hypothesis 2: Phases of mentoring and mentoring outcomes}

Regression analysis was conducted for the phases of mentoring as independent variables and each of the mentoring outcomes (skills transfer outcomes, knowledge transfer outcomes, entrepreneur resilience outcomes and business outcomes) as the dependent variable. The values indicating phases of mentoring had no numerical mathematical value, so dummy variables had to be created to split up the phases of

TABLE 6: Correlations between mentoring outcomes.

\begin{tabular}{|c|c|c|c|c|}
\hline Mentoring outcomes & Skills transfer outcomes & Knowledge transfer outcomes & Entrepreneur resilience outcomes & Business outcomes \\
\hline Skills transfer outcomes & - & Strong positive correlation & Strong positive correlation & Strong positive correlation \\
\hline Knowledge transfer outcomes & - & - & Strong positive correlation & Strong positive correlation \\
\hline Entrepreneur resilience outcomes & - & - & - & Strong positive correlation \\
\hline
\end{tabular}


mentoring variable. As described by Lee (2015), dummy variables are used to divide up one categorical variable, with value 1 indicating membership in a specific category and 0 showing non-membership in the specific category.

As the phase of mentoring was a categorical variable, three dummy variables were created with phase 1 as the reference as follows:

- dum_phase $2=1$ if the phase $=2$ and 0 otherwise

- dum_phase $3=1$ if the phase $=3$ and 0 otherwise

- dum_phase $4=1$ if the phase $=4$ and 0 otherwise.

Table 7 highlights the phases 2, 3 and 4 with reference to phase 1 . The results show that

- phase of mentoring has a statistically significant effect ( $p=0.026,0.020$ and 0.036$)$ with predictors of skills transfer outcomes; the relationship being positive but weak (standardised beta values $=0.247,0.287$ and 0.266 )

- phase of mentoring does not have a statistically significant effect ( $p=0.501,0.269$ and 0.315 ) with predictors of knowledge transfer outcomes; the relationship being positive but weak (standardised beta values $=0.075,0.137$ and 0.129)

- phase of mentoring has a statistically significant effect ( $p=0.015,0.032$ and 0.002$)$ with predictors of entrepreneur resilience outcomes; the relationship being positive but weak (standardised beta values $=0.269,0.261$ and 0.401 )

- phase of mentoring does not have a statistically significant effect ( $p=0.153,0.165$ and 0.202 ) with predictors of business outcomes; the relationship being positive but weak (standardised beta values $=0.160,0.172$ and 0.164 ).

In reviewing the results of the statistical tests for research hypothesis 2, it is concluded that the phases of mentoring have a relationship with skills transfer outcomes and entrepreneur resilience outcomes independently but not with knowledge transfer outcomes or business outcomes.

- In reviewing the results of the statistical tests for hypothesis $2 \mathrm{~A}$, it is concluded that the phases of mentoring have a relationship with skills transfer outcomes.

- In reviewing the results of the statistical tests for hypothesis 2B, it is concluded that the phases of mentoring do not have a relationship with knowledge transfer outcomes.

- In reviewing the results of the statistical tests for hypothesis $2 \mathrm{C}$, it is concluded that the phases of mentoring have a relationship with entrepreneur resilience outcomes.
- In reviewing the results of the statistical tests for hypothesis 2D, it is concluded that the phases of mentoring do not have a relationship with business outcomes.

Therefore, research hypothesis 2 was partially supported, finding that the phases of mentoring have a relationship with skills transfer outcomes and entrepreneur resilience outcomes independently but not with knowledge transfer outcomes or business outcomes. In this study, the phases of mentoring are bundled for testing and the outcomes highlighted, whereas Memon et al. (2015) indicate that the cultivation stage is the first stage of entrepreneurial learning although they do not specify what is learnt. Therefore, the findings in this study support the indication that learning occurs during the stages although the phases are not specified.

\section{Conclusion and practical implications}

The study makes a theoretical contribution through naming and grouping mentoring outcomes into four categories, namely, skills transfer outcomes, knowledge transfer outcomes, entrepreneur resilience and business outcomes. It is concluded that there is a relationship between the mentoring outcomes (skills transfer outcomes, knowledge transfer outcomes, entrepreneur resilience outcomes and business outcomes).

Furthermore, the study showed that phases of mentoring have a positive relationship with skills transfer outcomes and entrepreneur resilience outcomes, respectively, but not with knowledge transfer outcomes and business outcomes. This suggests that the respondents should make sure that they continue through all phases of long-term mentoring relationships. As the mentoring relationship goes through the different phases (which are initiation, cultivation, separation and redefinition), skills transfer outcomes and entrepreneur resilience outcomes would be independently attained. As highlighted by McKevitt and Marshall (2015:266), 'mentoring is a relationship and relationships are understood as giving rise to actionable knowledge'.

\section{Limitations of the study}

The data rest on entrepreneurs and small business owners' perceptions of learning through the mentoring relationship. It was not possible to verify what the person was saying as this was an online survey; however, there is no interviewer bias as the survey was self-administered. It appears most

TABLE 7: Regression analysis: Phases of mentoring and mentoring outcomes.

\begin{tabular}{|c|c|c|c|c|c|c|c|c|}
\hline \multirow{3}{*}{$\begin{array}{l}\text { Independent variable: } \\
\text { Phase of mentoring }\end{array}$} & \multicolumn{8}{|c|}{ Dependant variable } \\
\hline & \multicolumn{2}{|c|}{ Skills transfer outcomes } & \multicolumn{2}{|c|}{ Knowledge transfer outcomes } & \multicolumn{2}{|c|}{ Entrepreneur resilience outcomes } & \multicolumn{2}{|c|}{ Business outcomes } \\
\hline & $\begin{array}{l}\text { Standardised } \\
\text { beta value }\end{array}$ & $p$-value & $\begin{array}{l}\text { Standardised } \\
\text { beta value }\end{array}$ & $p$-value & $\begin{array}{l}\text { Standardised } \\
\text { beta value }\end{array}$ & $p$-value & $\begin{array}{l}\text { Standardised } \\
\text { beta value }\end{array}$ & $p$-value \\
\hline dum_phase 2 & $0.247 * *$ & 0.026 & 0.075 & 0.501 & $0.269 * *$ & 0.015 & 0.160 & 0.153 \\
\hline dum_phase 3 & $0.287 * *$ & 0.020 & 0.137 & 0.269 & $0.261^{* *}$ & 0.032 & 0.172 & 0.165 \\
\hline dum_phase 4 & $0.266 * *$ & 0.036 & 0.129 & 0.315 & $0.401 * * *$ & 0.002 & 0.164 & 0.202 \\
\hline$R^{2}$ & 0.029 & - & 0.007 & - & 0.05 & - & 0.011 & - \\
\hline$F$ (p-value) & 2.029 & 0.111 & 0.453 & 0.716 & 3.577 & 0.015 & 0.773 & 0.511 \\
\hline
\end{tabular}

$* *, p<0.05 ; * * *, p<0.01$ (Indicates statistical significance) 
mentees have had more than one mentoring relationship, but the research did not interrogate each relationship separately. Prior knowledge as an extraneous variable was not tested, as it could affect the outcomes of mentoring.

The research assumed that the respondents would relate their answers to the most recent mentoring relationship. As stated by Mejia and Gopal (2015:4), 'entrepreneurship requires embedding the researcher within the institutional environment'. This study was not done for a specific institution. The survey was sent to any entrepreneurs or small business owners who had been mentored or were still being mentored. The differences in mentoring organisations could account for differences in mentoring satisfaction and mentoring outcomes.

\section{Recommendations for future research}

Practical recommendations entail creating honest relationships with mentees who are not transactional by understanding mentees' business environment to give appropriate advice. Furthermore, establishing mentoring programmes that ensure transfer of skills, knowledge, entrepreneur resilience and business outcomes. Also, by increasing the employment of mentors who have run businesses before and also engaging existing entrepreneurs and small business owners to become mentors.

The focus of this study was on the mentees' perspective (entrepreneurs and small business owners). Future research could include a qualitative, longitudinal study that addresses perspectives of both mentors and mentees. In light of mentees having been in more than one mentoring relationship, future research needs to interrogate each mentoring relationship separately.

\section{Acknowledgements}

The views expressed in this article are our own and not an official position of the institution or funder.

\section{Competing interests}

The authors declare that they have no financial or personal relationships that may have inappropriately influenced them in writing this article.

\section{Authors' contribution}

C.K. is the first author who conceptualised the research article, conducted literature review, handled data collection and analysis and wrote the article and was completed under the guidance of M.N.M.

\section{References}

Ayer, N., 2010, 'Learning from mentors: Perspectives of South African entrepreneurs', Unpublished master's dissertation, University of Pretoria, Pretoria.

BarNir, A., Watson, W.E. \& Hutchins, H.M., 2011, 'Mediation and moderated mediation in the relationship among role models, self-efficacy, entrepreneurial career intention, and gender', Journal of Applied Social Psychology 41(2), 270-297. https://doi.org/10.1111/j.1559-1816.2010.00713.x
Barrett, R., 2006, 'Small business learning through mentoring: evaluating a project', Education + Training 48(8/9), 614-616. https://doi.org/10.1108/004009106107 10047

Bayron, C.E., 2013, 'Social cognitive theory, entrepreneurial self-efficacy and entrepreneurial intentions: Tools to maximize the effectiveness of formal entrepreneurship education and address the decline in entrepreneurial activity', entrepreneurship
Griot 6(1), 66-77.

Beavers, A.S., Lounsbury, J.W., Richards, J.K., Huck, S.W., Skolits, G.J. \& Esquivel, S.L. 2013, 'Practical considerations for using exploratory factor analysis in educational research practical assessment', Research \& Evaluation 18(6), 1-13.

Botha, M. \& Esterhuyzen, E., 2012, 'The perceived capabilities and willingness of South African small business owners to act as business mentors', African Journal of Business Management 11(4), 12101-12113.

Brien, E.O. \& Hamburg, I., 2014, 'Supporting sustainable strategies for SMEs through training, cooperation and mentoring', Higher Education Studies 4(2), 61-69. https://doi.org/10.5539/hes.v4n2p61

Bryman, A. \& Bell, E., 2015, Business research methods, 4th edn., Oxford University Press, Oxford, United Kingdom.

Cline, M., 2011, 'Paying it forward: The relationship between mentoring and perceived ESE of Jewish South African Entrepreneurs', Unpublished master's dissertation, University of Witwatersrand, Johannesburg.

Cooper, D.R. \& Schindler, P.S., 2011, Business research methods, 11th edn., McGraw-Hill, New York.

Davies, C., 2017, 'Formal mentorship and entrepreneurial learning the case of a support programme in the Western Cape Clothing Sector', Unpublished master's dissertation, University of the Western Cape, Western Cape.

Gwija, S.A., Eresia-Eke, C. \& Iwu, C., 2014, 'Assessing the impact of support structures and initiatives to youth entrepreneurship development in a selected Township in the Western Cape Province of South Africa', Mediterranean Journal of Social Sciences, viewed 05 November 2014, from http://www.mcser.org/journal/index. $\mathrm{php} / \mathrm{mjss} / \mathrm{rt} / \mathrm{printerFriendly/1879/0}$

Han, L., Benson, A. Chen, J.J. \& Zhang, S., 2014, 'The use and impacts of bank support on UK small and medium-sized enterprises', International Small Business Journal 32(1), 61-80. https://doi.org/10.1177/0266242612455008

Harinie, L.T., Sudiro, A., Rahayu, M. \& Fatchan, A., 2017, 'Study of the Bandura's social cognitive learning theory for the entrepreneurship learning process', Social Sciences 6(1), 1-6. https://doi.org/10.11648/j.ss.20170601.11

Herrington, M. \& Kew, J., 2015/2016, GEM South African Report 20 years of democracy, viewed 20 January 2017, from http://ideate.co.za/wp-content/uploads/2016/05/ gem-south-africa-2015-2016-report.pdf

Kamyabi, Y. \& Devi, S., 2011, 'Use of professional accountants' advisory services and its impact on SME performance in an emerging economy: A resource-based view', Journal of Management and Sustainability 1(1), 43-55. https://doi.org/10.5539/ jms.v1n1p43

Koopman, R.G.M., 2013, 'Coaching and mentoring entrepreneurs: More definitions won't work', in RENT XXVII-Research in Entrepreneurship and Small Business 2013 : Entrepreneurship, institutions and competitiveness, viewed 22 January 2015, from https://ris.utwente.nl/ws/portalfiles/portal/13051070

Kram, K.E., 1983, 'Phases of the mentor relationship', Academy of Management Journal 26, 608-625. https://doi.org/10.2307/255910

Kyrgidou, L.P. \& Petridou, E., 2013, 'Developing women entrepreneurs' knowledge, skills and attitudes through e-mentoring support', Journal of Small Business and Enterprise Development 20(3), 548-566. https://doi.org/10.1108/JSBED-04-20130061

Laukhuf, R.L. \& Malone, T.A., 2015, 'Women entrepreneurs need mentors', International Journal of Evidence Based Coaching and Mentoring 13(1), 70-86, International Journal of Evidence Based Coaching and Mentoring 13(1), 70-86,
viewed 18 August 2015, from http://www.business.brookes.ac.uk/research/ viewed 18 August 2015, from
areas/coachingandmentoring

Lawless, M., 2009, 'The influence of life coaching on entrepreneurs' goal planning and attainment', Unpublished master's dissertation, Waterford Institute of Technology, attainment', Unpublist

Lee, G.J., 2015, Business statistics made easy in SAS, 1st edn., Silk Route Press, Randtjiesfontein, South Africa.

Leedy, P.D. \& Ormrod, J.E., 2013, Practical research planning and design, 10th edn., Pearson, Boston, MA.

Leidenfrost, B., Strassnig, B., Schütz, M., Carbon, C.C. \& Schabmann, A., 2014, 'The impact of peer mentoring on mentee academic performance: Is any mentoring style better than no mentoring at all?', International Journal of Teaching and Learning in Higher Education 26(1), 102-111.

Radu Lefebvre, M. \& Redien Collot, R., 2013, “How to do things with words": The discursive dimension of experiential learning in entrepreneurial mentoring dyads' Journal of Small Business Management 51(3), 370-393. https://doi.org/10.1111/ jsbm.12022

Makhado, A.E., 2015, 'The effectiveness of mentorship programme of Mogale City local municipality for small, medium and micro enterprises', Unpublished master's dissertation, University of Pretoria, Pretoria.

Makin, L., 2012, The benefits of business mentoring to business owners of established small businesses in the United Kingdom (Research findings summary report), viewed 22 January 2016, from http://makinithappen.co.uk/Research.html

Martin, R.L., 2008, 'An investigation into the knowledge requirements for entrepreneur and small business support practitioners', Unpublished doctoral thesis, University of Pretoria, Pretoria. 
Matabooe, M.J., Venter, E. \& Rootman, C., 2016, 'Understanding relational conditions necessary for effective mentoring of black-owned small businesses: A South African perspective', Acta Commercii-Independent Journal in the Management African perspective', Acta Commercii-Independent Journal in
Sciences 16(1), 1-11. https://doi.org/10.4102/ac.v16i1.327

McKevitt, D. \& Marshall, D., 2015, 'The legitimacy of entrepreneurial mentoring', International Journal of Entrepreneurial Behaviour \& Research 21(2), 263-280. https://doi.org/10.1108/IJEBR-05-2014-0089

Mejia, J. \& Gopal, A., 2015, Now and later? Mentorship, investor ties and new venture performance in entrepreneurial seed-Accelerators, Working paper, Robert $\mathrm{H}$. Smith School of Business, University of Maryland.

Memon, J., Rozan, M.Z.A., Ismail, K., Uddin, M. \& Daud, D., 2015, 'Mentoring an entrepreneur: Guide for a Mentor', Sage Open 5(1), 1-10. https://doi.org/ $10.1177 / 2158244015569666$

Mills, J., Barakat, S. \& Vyakarnam, S., 2013, 'Impact of mentoring and peer-learning within a global entrepreneurship programme', Unpublished paper delivered at the Conference of the Institute for Small Business and Entrepreneurship (ISBE 2013), viewed 30 July 2015, from http://www.academia.edu/3272663/Impact_of mentoring_and_peer-learning_within_a_global_entrepreneurship_programme

Moulson, N., 2015, 'How millennial generation entrepreneurs use mentors to improve business performance', Doctoral dissertation, Walden University.

Nicoleta, G. \& Chioncel, C.P., 2014, 'The role of mentoring in entrepreneurship training PREMIO case study', Unpublished paper delivered to the 17th National Conference on Electrical Drives (CNAE 2014), viewed 07 August 2015, from http://anale-ing. uem.ro/2014/331.pdf

Nieman, G.H. \& Nieuwenhuizen, C., 2009, Entrepreneurship: A South African perspective, 2nd edn., Van Schaik, Pretoria.

Poulsen, K.M., 2013, 'Mentoring programmes: Learning opportunities for mentees, for mentors, for organisations and for society', Industrial and Commercial Training 45(5), 255-263. https://doi.org/10.1108/ICT-03-2013-0016

Purcell, G., 2013, 'Entrepreneurial assistance across the ocean: An examination of the effectiveness of international mentoring as a support service for entrepreneurs in Samoa: A thesis presented in partial fulfilment of the requirements for the degree of Master of Philosophy in Development Studies at Massey University, Palmerston North, New Zealand', Doctoral dissertation, Massey University.

Republic of South Africa, 1996, National Small Business Act of 1996, viewed 21 March 2015, from https://www.thedti.gov.za/sme_development/docs/act.pdf
Rigg, C. \& O'Dwyer, B., 2012, 'Becoming an entrepreneur: Researching the role of mentors in identity construction', Education + Training 54(4), 319-329. https:// doi.org/10.1108/00400911211236181

Schlosser, F., 2012, 'Taking an active approach in entrepreneurial mentoring programmes geared towards immigrants', Journal of Entrepreneurship 21(2), 201-221. https://doi.org/10.1177/0971355712449411

Sijde, P. \& Weijman, G., 2013, 'Benefits and impact of mentoring for entrepreneurs: The entrepreneur's perspective', International Journal of Human Resource Studies 3(4), 194-204. https://doi.org/10.5296/ijhrs.v3i4.4581

Stavropoulou, O. \& Protopapa, S., 2013, 'A strengths-based approach to mentoring women entrepreneurs: How to free the strengths within them', Journal of Innovation and Entrepreneurship 2(13), 1-10. https://doi.org/10.1186/2192 5372-2-13

Steele, P.K., 2016, Effective general entrepreneurial learning programs for SME development, Capstone Collection, Paper 2903, viewed 12 November 2016, from http://digitalcollections.sit.edu/capstones

St-Jean, E. \& Audet, J., 2009, 'Factors leading to satisfaction in a mentoring scheme for novice entrepreneurs', International Journal of Evidence Based Coaching and Mentoring 7(1), 148-161.

St-Jean, E. \& Audet, J., 2012, 'The role of mentoring in the learning development of the novice entrepreneur', International Entrepreneurship and Management Journal 8(1), 119-140. https://doi.org/10.1007/s11365-009-0130-7

Swanepoel, E., Strydom, J.W. \& Nieuwenhuizen, C., 2010, 'An empirical analysis of a private company's corporate social investment in SMME development in South Africa', South African Business Review 14(1), 58-78.

Timmons, J.A. \& Spinelli, J., 2009, New venture creation: Entrepreneurship for the 21st century, 8th edn., McGraw-Hill Irwin Press, New York.

Triodos Facet, B.V., 2011, Lessons on virtual business incubation services, Information for Development Program, World Bank, The Netherlands.

Van Auken, H. \& Carraher, S., 2013, 'Influences on frequency of preparation of financial statements among SMEs', Journal of Innovation Management 1(1), 143-157.

Watson, G.E.H., 2004, 'A situational analysis of entrepreneurship mentors in South Africa', Unpublished master's thesis, University of South Africa, Pretoria. 